\title{
Choice reaction time and behavioral hypotheses: The effects of learning sequential redundancies
}

\author{
IRA H. BERNSTEIN AND CHARLES REESE \\ THE UNIVERSITY OF TEXAS AT ARLINGTON
}

Eleven Ss learned the sequential redundancies present in a choice reaction time $(R T)$ task, as inferred from their ability to verbally anticipate the stimulus event to a designated criterion. These Ss showed a transition from choice to simple $R T$. Five $S s$ did not learn the redundancies to this criterion. Except for a first trial RT decrement, they behaved as did a control group of eight $S s$ in remaining at the choice $R T$ level. The results suggested a technique useful in the study of cognitive determinants of $R T$.

A pair of recent studies (Bernstein \& Reese, 1965; Bernstein et al, 1967) examined the relationship between pretrial guesses as to the expected stimulus event in a choice reaction time (RT) experiment and subsequent RT. Despite the random nature of the stimulus sequence and the use of trained Ss over a long series of trials, a systematic relationship was found between RT and these verbal reports in the above studies. RT was faster when the pretrial guess or behavioral hypotheses was correct $(\mathrm{BH}+)$ than when it was incorrect (BH-).

The present experiment utilized verbal report techniques to examine the effects of sequential stimulus redundancy upon RT. It was hypothesized that Ss given a sequential redundancy will show a decrease in RT only after they have gained knowledge of the redundancy, and that Ss' degree of knowledge of the redundancy could be evaluated independently of RT changes through use of pretrial verbal reports.

Subjects

Twenty-four undergraduates enrolled in the summer session introductory psychology classes at Arlington State College comprised the sample. Each served for a $1 \mathrm{~h}$ session and received course credit for participation. Ss were assigned to an experimental (E) and a control (C) group randomly in order of appearance on a 2:1 ratio. Five males and three females were assigned to the $C$ group and 10 males and six females to the experimental group.

Procedure

Each session consisted of a series of 48 practice trials, 64 baseline trials, and 128 learning trials. The baseline trials served to provide estimates of RT to either one or eight stimulus alternatives. These RTs were obtained to estimate simple and choice points, respectively. Half of the Ss were informed which stimulus event would next occur in order to estimate simple RT. The remaining Ss were not so informed in order to estimate choice RT. Half of each of these groups of Ss were given baseline estimation trials prior to the learning trials and the remainder following the learning trials. However, as a preliminary analysis falled to indicate a significant difference between the baseline trials given before the learning trials and the baseline trials given after the learning trials, these data were pooled.

Ss were assigned to the two learning groups, E and $C$, independently of their assignment to baseline conditions. Practice, baseline, and the C group's "learning" trials were organized into 4,4 , and 8 randomized blocks of 16 trials each, respectively, with the eight stimulus events occurring twice per trial block. The eight stimulus events formed a redundant cycle for the $\mathrm{E}$ group during the learning trials, although for purposes of data analysis, a trial block also consisted of 16 trials.

The instructions given to both $\mathrm{E}$ and $\mathrm{C}$ groups on the learning trials were alike and stated that the pattern may or may not be redundant for them, but to respond as rapidly as they could in either event. Ss were told that RT would be shortened if they were given a sequential pattern and could learn it.

The foreperiod was a constant $2 \mathrm{sec}$, and the intertrial interval was approximately $10 \mathrm{sec}$ as determined by S's readiness for the next trial to occur and his emission of a BH when appropriate. These BH reports were obtained by asking all Ss to name which of the eight stimulus events they expected. BH reports were obtained for all Ss on learning trials, for Ss on choice baseline trials, but not, of course, for Ss on simple baseline trials.

\section{Apparatus}

The apparatus consisted of an amperite delay tube which timed the foreperiod delay, a .01 sec Lafayette clock which timed the RTs and a specially constructed stimulus display and response module. The stimulus display was similar to the one employed by Bernstein \& Reese (1965) and consisted of eight neon NE 51 glow lamps, arranged in a four column by two row rectangular array, with adjacent bulbs spaced 1-in. apart. A ninth NE 51 glow lamp was located immediately above this pattern and served as a warning light. The response panel was located underneath the stimulus display and consisted of four double throw PBX telephone switches.

Results

Ss in the E group were classified as aware of the redundancy (Group $A, N=11$ ) or unaware (Group $U, N=5$ ) on the basis of whether or not they reached a criterion of eight consecutive BH+ trials or not. Analysis of the verbal report data indicated that Group $A$ reached a uniformly high level of learning of the redundancy; on the final trial block, the average number of $\mathrm{BH}+$ trials was 15 of 16. In contrast, the U group did not differ signif- 


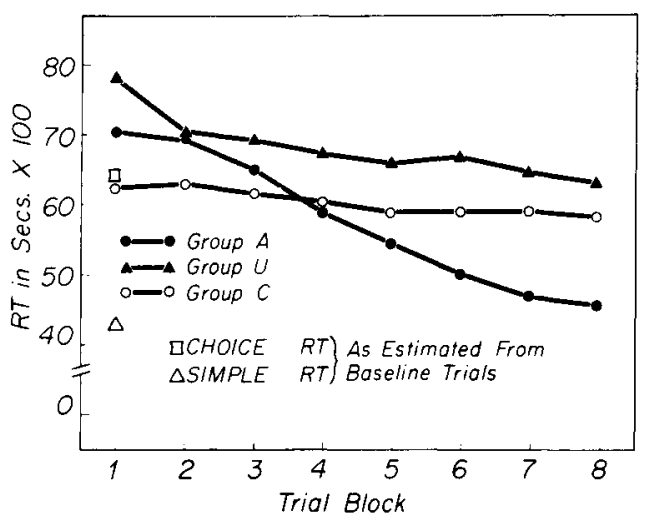

Fig. 1. Mean of the trial block RT medians for simple and choice baseline trials and the aware (A), unaware (U), and control groups on the learning trials.

icantly across trials from the $\mathrm{C}$ group in mean number of $\mathrm{BH}+$ trials.

The RT data for baseline and learning trials was the median RT on each trial block. In Fig. 1 the baseline means as a function of stimulus uncertainty and the learning trends for the $\mathrm{A}, \mathrm{U}$, and $\mathrm{C}$ groups are presented.

Two sets of analyses were made upon the learning data. First, performance on the first and last block of learning trials was compared with performance on both choice and simple baseline trials. These analyses indicated that on trial Block 1 the mean RT for Group $U$ was longer than both the simple and choice RT means $(t=5.93, p<.001$, and $t=2.36, p<.05$, respectively). Both the $A$ and $C$ groups differed from the simple RT mean $(t=6.75$ and $4.00, p<.001$, respectively) and did not differ from the choice RT means $(t=.46$ and 1.52, respectively). On trial Block 8 , both Groups $U$ and $C$ differed significantly from the simple RT mean $(t=4.64$ and $4.40, p<.001$, respectively) but did not differ from the choice RT means $(t=.22$ and 1.68 , respectively). Conversely, Group A did not differ from the simple RT mean $(t=1.14)$ but did differ from the choice RT mean $(t=6.00, p<.001)$ on trial Block 8. The error terms for the $t$ tests were obtained from simple analyses of variance done separately for Trials 1 and 8 . The comparisons for the $\mathrm{A}, \mathrm{U}$, and $\mathrm{C}$ groups had 10,4 , and 7 df, respectively. All comparisons were two-tailed.

In a second set of analyses, the RT data were examined for each group across trials in a nested analysis of variance format. The overall Group $C$ trend was not significant $(\mathrm{F}<1, \mathrm{df}=7 / 147$ ) but the linear component of this trend, representing a practice effect, was significant $(F=4.42, \mathrm{df}=1 / 147, \mathrm{p}<.05)$. For the $\mathrm{U}$ group both the overall trend was significant ( $F=3.68$, df $=$ $7 / 147, p<.01)$ as was the linear component of this trend $(F=20.65$, df $=1 / 147, p<.001)$. For trial Blocks $1-8$, the overall trend for the $U$ group was greater than the trend for the $C$ group $(F=4.95, d f=7 / 7, p<.05)$. This seems to be due to the poor performance of Group $U$ on trial Block 1 rather than to any subsequent effects. Analyses of the two groups' performance on trial Blocks 2-8 indicated that they were homogeneous $(F=1.47$, $d f=6 / 6)$. Also, a supplemental analysis comparing the performance of the $\mathrm{C}$ and $\mathrm{U}$ groups indicated that the slightly longer RTs for the former group was not statistically significant ( $F=1.35, \mathrm{df}=1 / 21$ ) nor was the groups by trials interaction $(F=1.32, d f=7 / 147$ ). As the data in Fig. 1 also indicate, the overall trend for the A group was highly significant $(F=33.0, \mathrm{df}=7 / 1 \pm 7, \mathrm{p}<$ .001 ) as was the linear component of this trend ( $F=$ 222.60, df $=1 / 147, \mathrm{p}<.001$ ).

\section{Discussion}

Except for the degradation in RT on the first block for the $U$ group, the results of the present experiment clearly indicate that Ss who do not learn a redundancy, as inferred from verbal report, perform at the level of a control group given a random sequence. In contrast, those Ss whose verbal reports indicate that they have learned the redundancy showed a transition in their RT performance in keeping with their knowledge of the stimulus sequence.

Fitts et al (1963) have proposed a model relevant to the present situation which assumes that adjustments to stimulus redundancies are mediated by a Baysian decision mechanism. Supporting data for the model was derived from an experiment in which Ss were explicitly informed of a frequency imbalance redundancy. Their findings supported the model as RT changes over sessions reflected the development of a posterior probability strategy and were a linear function of the amount of redundancy.

The present data suggests verbal reports to be a technique useful in a more detailed examination of the Fitts et al (1963) model. Use of verbal reports allows independent examination of the changes in posterior probabilities separately from RT. Likewise it is not necessary to provide Ss with explicit information about the redundancy; hence, the model can be extended to learning tasks in the traditional sense. In essence, verbal reports can provide an operational definition of posterior probability which is independent of both the experimentally defined redundancy and the S's RT.

\section{References}

BERNSTEIN, I. H., \& REESE, C. Behavioral hypotheses and choice reaction time. Psychon. Sci, 1965, 3, 259-260.

BERNSTEIN, I. H., SCHURMAN, D. L., \& FORESTER, G. Choice reaction time as a function of stimulus uncertainty, response uncertainty and behavioral hypotheses. J. exp. Psychol., 1967, in press.

FITTS, P. M., PETERSON, J. R., \& WOLPE, G. Cognitive aspects of information processing: II. Adjustments to stimulus redundancy. $J$. exp. Psychol., 1963, 65, 423-432.

\section{Note}

1. Supported by NIMH Grants $11173-01$ and $12530-01$ to the senior author. The authors are grateful to Mr. David Phillips for construction of the stimulus display and response model and to Dr. Erwin M. Segal for his comments. 